\title{
Influence of bone density on morphologic cement penetration in minimally invasive tibial unicompartmental knee arthroplasty: an in vitro cadaver study
}

Christian B. Scheele ${ }^{1,2^{*}}$, Matthias F. Pietschmann ${ }^{1}$, Christian Schröder ${ }^{1}$, Igor Lazic ${ }^{2}$, Thomas M. Grupp ${ }^{1,3}$ and Peter E. Müller ${ }^{1}$

\begin{abstract}
Background: Unicompartmental knee arthroplasty is an established treatment option for anteromedial osteoarthritis. However, large registry studies report higher rates of aseptic loosening compared to total knee arthroplasty. The objective of this study was to assess the impact of bone density on morphological cement penetration. Moreover, an alternative regional bone density measuring technique was validated against the established bone mineral density assessment.
\end{abstract}

Methods: Components were implanted on the medial side of 18 fresh-frozen cadaver knees using a minimally invasive approach. Bone density has been quantified prior to implantation using Hounsfield units and bone mineral density. Morphological cement penetration has been assessed in different areas and was correlated with local bone density.

Findings: A highly significant correlation between Hounsfield units and trabecular bone mineral density was detected $(r=0.93 ; P<0.0001)$, and local bone density was significantly increased in the anterior and posterior area $(P=0.0003)$. The mean cement penetration depth was $1.5(\mathrm{SD} 0.5 \mathrm{~mm})$, and cement intrusion into trabecular bone was interrupted in $31.8 \%$ (SD 23.7\%) of the bone-cement interface. Bone density was correlated significantly negative with penetration depth $(r=-0.31 ; P=0.023)$ and positive with interruptions of horizontal interdigitating $(r=+0.33 ; P=0.014)$. Cement penetration around the anchoring peg was not significantly correlated with bone density.

Interpretation: Areas with high bone density were characterized by significantly lower penetration depths and significantly higher areas without cement penetration. Anchoring pegs facilitate cement intrusion mechanically. Regional quantification of bone density using Hounsfield units is a simple but valuable extension to the established determination of bone mineral density.

Keywords: Unicompartmental knee artrhroplasty, UKA, Bone density, BMD, Cementation, Minimally invasive

\footnotetext{
* Correspondence: christian.scheele@mri.tum.de

1 Department of Orthopaedics, Physical Medicine and Rehabilitation,

University Hospital, LMU Munich, Munich, Germany

${ }^{2}$ Department of Orthopedics and Sports Orthopedics, Klinikum rechts der

Isar, Technical University Munich, Ismaninger Str. 22, 81675 Munich, Germany

Full list of author information is available at the end of the article
}

(c) The Author(s). 2019 Open Access This article is distributed under the terms of the Creative Commons Attribution 4.0 International License (http://creativecommons.org/licenses/by/4.0/), which permits unrestricted use, distribution, and reproduction in any medium, provided you give appropriate credit to the original author(s) and the source, provide a link to the Creative Commons license, and indicate if changes were made. The Creative Commons Public Domain Dedication waiver (http://creativecommons.org/publicdomain/zero/1.0/) applies to the data made available in this article, unless otherwise stated. 


\section{Background}

In view of excellent functional results, good long-term survivorship, and advantages in terms of cost efficiency, unicompartmental knee arthroplasty (UKA) can make a significant contribution to meet the rapidly growing demand for knee arthroplasty [1-5]. Since the aseptic loosening of the tibial component, misinterpretation of radiolucent lines and cementation errors remain major reasons for revision in UKA [6-9]; improvements of the interface between prosthesis, cement, and trabecular bone, as well as the optimization of minimally invasive surgical techniques, are of outstanding importance $[10$, 11].

While former studies focused on levers to improve cemented fixation that can be controlled by the surgeon, such as bone bed preparation, cementing technique, or surgical access [11-17], little is known about the impact of bone density, which can hardly be altered, on cemented tibial fixation in UKA.

The goal of this study was to quantify the impact of regional bone density on different morphological aspects of cement penetration in minimally invasive UKA. In addition, the reliable applicability of Hounsfield unit (HU) measurement, which is a simple but precise tool for local quantification of bone density, has been validated against the established method of bone mineral density (BMD).

\section{Methods}

Eighteen fresh-frozen human cadaver knees (age 72.2, SD 14.9 years, 4 females, 14 males) were used for this in vitro study. CT scans (Sensation 64 Somatom, Siemens AG Munich, Germany) of all tibiae were acquired prior to the implantation in order to exclude specimens with osseous abnormalities and to quantify BMD. Cortical and trabecular BMD [milligrams $\left(\mathrm{Ca}^{2+} \mathrm{HA}\right) /$ milliliter] were determined using Syngo Osteo CT software (Siemens AG Munich, Germany) on the proximal tibia in seven layers each in $3 \mathrm{~mm}$, using a relative calibration to water $(0 \mathrm{HU})$ and calcium $(200 \mathrm{HU})$. Correspondingly, local bone density was determined by measuring the mean $\mathrm{HU}$ of six regions of interest (ROI) per slice, $1.6 \mathrm{~cm}^{2}$ each, in the anterior, central, and posterior area of the medial and lateral tibial plateau (Fig. 1). To capture the relevant area of implantation, both evaluations started in the most cranial slice without visible cortical bone or subchondral sclerosis and assessed $2 \mathrm{~cm}$ distally.

UKAs were implanted on the medial side of each knee via a minimally invasive approach without eversion of the patella. Tibial resection was performed with an anatomical posterior slope and the removal of the cartilage in all areas of the tibial plateau was ensured intraoperatively. Bone preparation was performed using pulsatile jet lavage (Pulsavac Plus, Zimmer Biomet, USA) and a high viscosity bone cement (Palacos ${ }^{\ominus}$ R 20 g powder/10

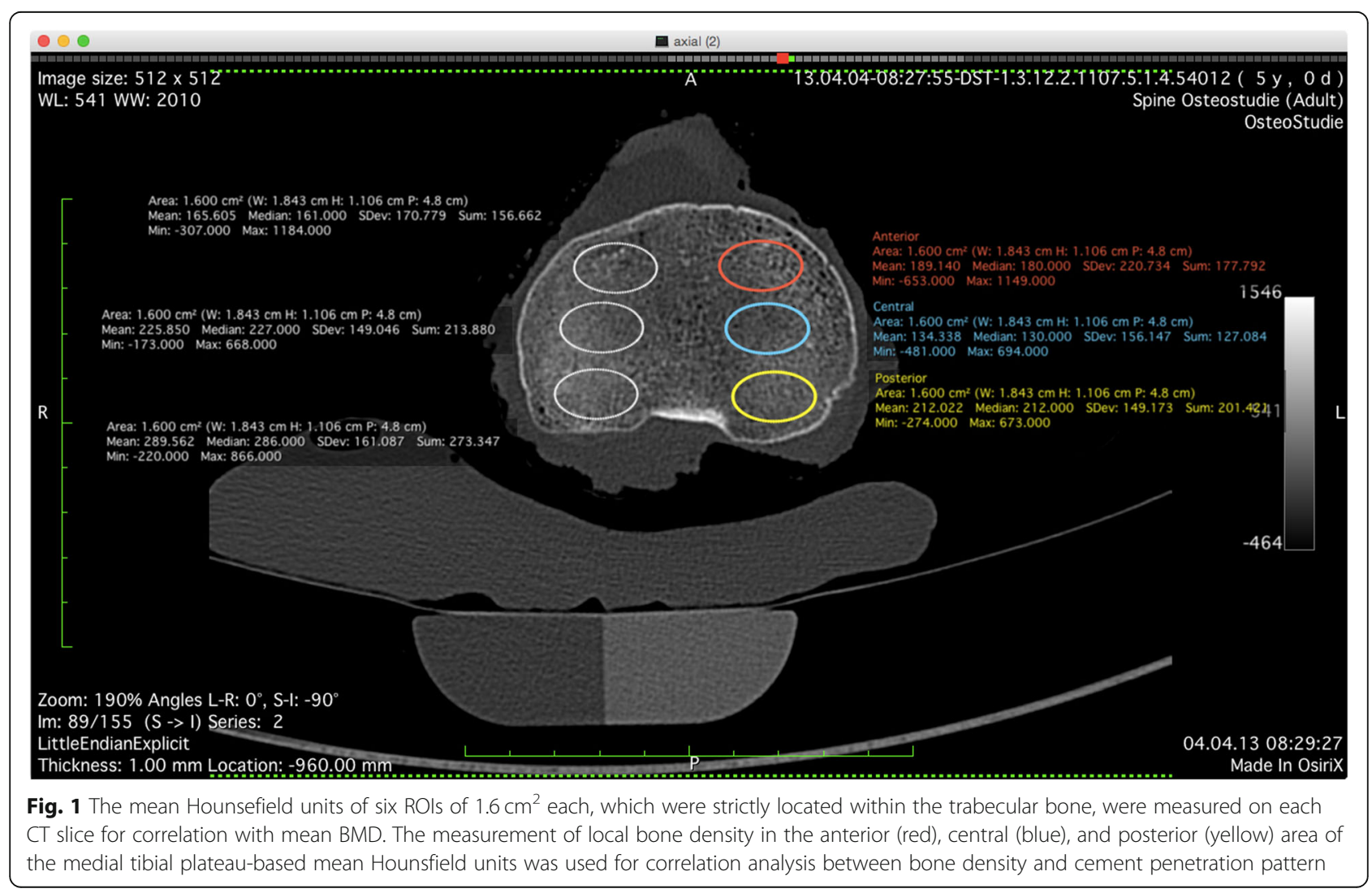


ml monomer, Heraeus Medical Wehrheim, Germany) was mixed manually for cemented fixation. The implantation of the components was performed according to the manufacturer's instructions (Univation ${ }^{\circ} \mathrm{X}$, Aesculap Tuttlingen, Germany) and all operations were performed by one experienced orthopedic surgeon. The knees were then positioned in $45^{\circ}$ flexion and a spacer was inserted to ensure adequate pressurization during polymerization of the cement.

Afterwards, the surrounding soft tissue was removed and the medial tibial plateaus with the cemented tibial trays were dissected (sagittal plane, at the eminentia intercondylaris; transversal plane, $20 \mathrm{~mm}$ below the tibial plateau). The 18 specimens were then imbedded in Technovit 4004 (Technovit 4004, Kulzer GmbH, Hanau, Germany) and cut into 10 frontal slices of identical thickness. Scans with a resolution of $100 \mathrm{pixel} / \mathrm{mm}$ made the implant-cement-bone interface accessible for morphologic evaluation using Adobe (Photoshop CS6, Adobe, San Jose, USA). Morphologic indicators of cementation were evaluated on both sides of nine cuts through the specimen. The anterior three serial cuts through the implant-cement-bone interface represented the anterior area, the central three cuts represented the central area and the posterior three cuts represented the posterior area of the medial tibial plateau.

The average total cement thickness was calculated by dividing the total area of bone cement by the length of the prosthesis (white and purple area, black arrow in Fig. 2). Cement mantle thickness was calculated by dividing the cement area above the resection line (white in Fig. 2) by the length of the cement-prosthesis interface (defined as contact between the white area and tibial component). Cement penetration depth was calculated by dividing the cement area below the resection line (purple in Fig. 2) by the length of the prosthesis. Furthermore, the length proportion of the horizontal underside of the tibial component (zone 1) without visible cement intrusion into the trabecular bone was determined (Fig. 3). Finally, the proportion of interfaces with visible cement interdigitation in the area adjacent to the anchoring peg (zone 2) of the prosthesis was documented.

For correlation with morphological cement penetration, bone density is quantified using $\mathrm{HU}$, as this allows selective density measurements in the individually investigated subareas of the tibial head.

Results in the text are presented as an arithmetic mean, standard deviation, and minimum and maximum of the evaluated values. To calculate Pearson's correlation coefficient between BMD and HU, all six ROIs per CT slice were taken into account. Differences in bone density in the different ROIs were analyzed using repeated measures ANOVA and Bonferroni's multiple comparison test. The effect of bone density on cement penetration was examined by calculating regression lines and Pearson's correlation coefficients based on all 54 ROIs. All tests were two-sided and a $P$ value of 0.05 was considered significant. Statistical analysis was performed with GraphPad Prism 5 (GraphPad Software, Inc., La Jolla, USA).

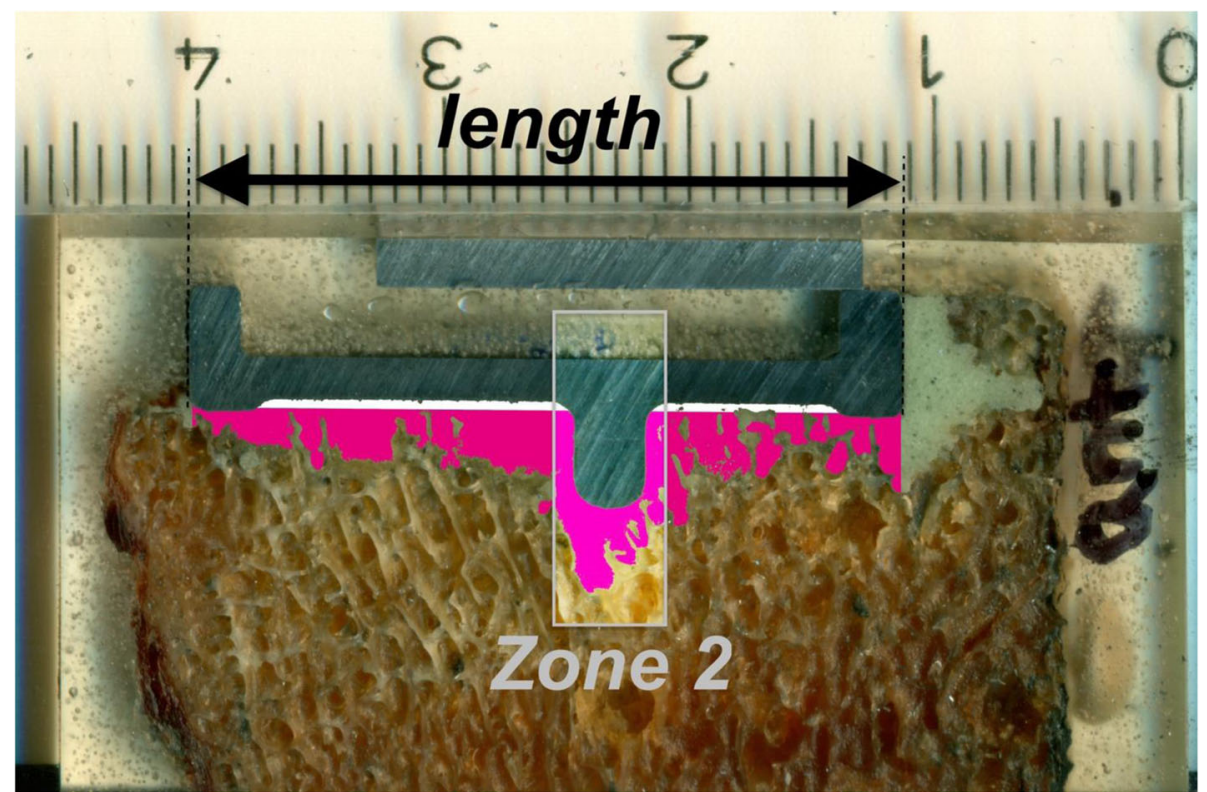

Fig. 2 Image of the prosthesis-cement-bone interface: white, cement mantle (above resection line); purple, cement penetration (below resection line). The area adjacent to the anchoring peg was defined additionally as "zone 2" 


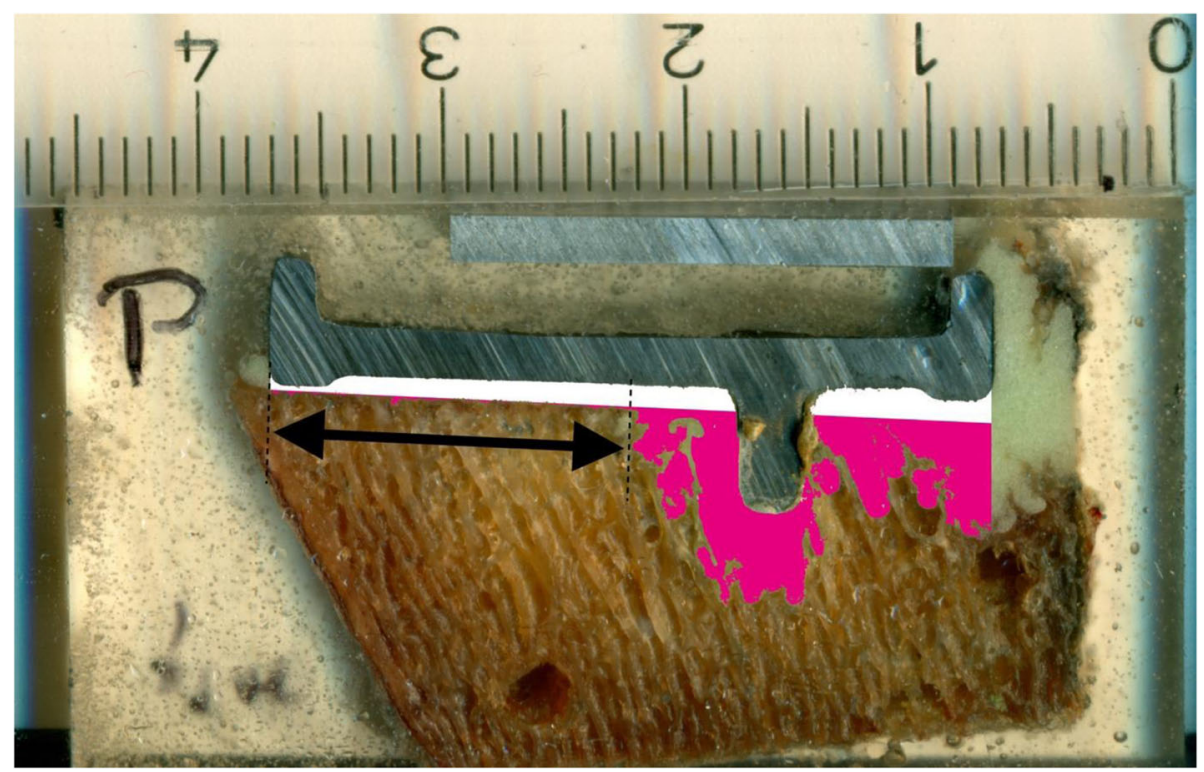

Fig. 3 Area without visible cement penetration of bone cement into the trabecular bone in zone 1 (arrow)

\section{Results}

The mean cortical BMD was 327.7 (SD $99.4 \mathrm{mg} / \mathrm{ml}$ ) [185.8-535.6], mean trabecular BMD was 103.6 (SD $29.5 \mathrm{mg} / \mathrm{ml}$ ) [67.4-183.0], and mean $\mathrm{HU}$ was 154.0 (SD 47.8) [92.0-252.8]. Between the trabecular BMD and $\mathrm{HU}$, a highly significant correlation was detected with a correlation coefficient of $r=0.93$ ( $P<0.0001$; Fig. 4). The correlation between the cortical BMD and HU was $r=$ $0.65(P=0.0037)$. The correlation between age and HU was not significant $(r=-0.36 ; P=0.1414)$.
The mean HU was 168.0 (SD 65.6) [83.1-294.1] in the anterior, 124.1 (SD 41.8) [55.2-215.7] in the central and 175.0 (SD 56.2) [94.3-295.5] in the posterior area of the medial tibial plateau, demonstrating significant differences $(P=0.0003)$. Differences between the anterior and central and between the central and posterior area were significant $(P<0.05$; Fig. 5$)$.

Based on all 54 ROIs, the mean total cement thickness was 2.1 (SD 0.6) [0.9-3.8], mean cement mantle thickness was 0.8 (SD 0.6) [0.0-2.8], and mean cement penetration

\section{$r=+0.93$}

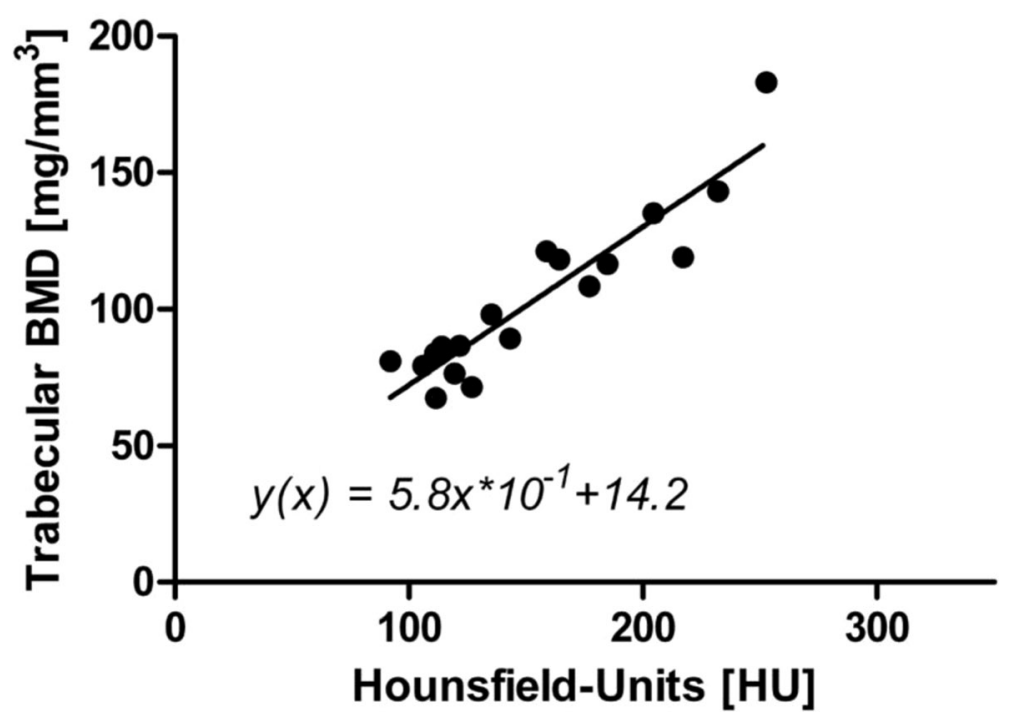

Fig. 4 Correlation between $\mathrm{BMD}$ and $\mathrm{HU}$ 


\section{Bone density \\ in the tibial head}

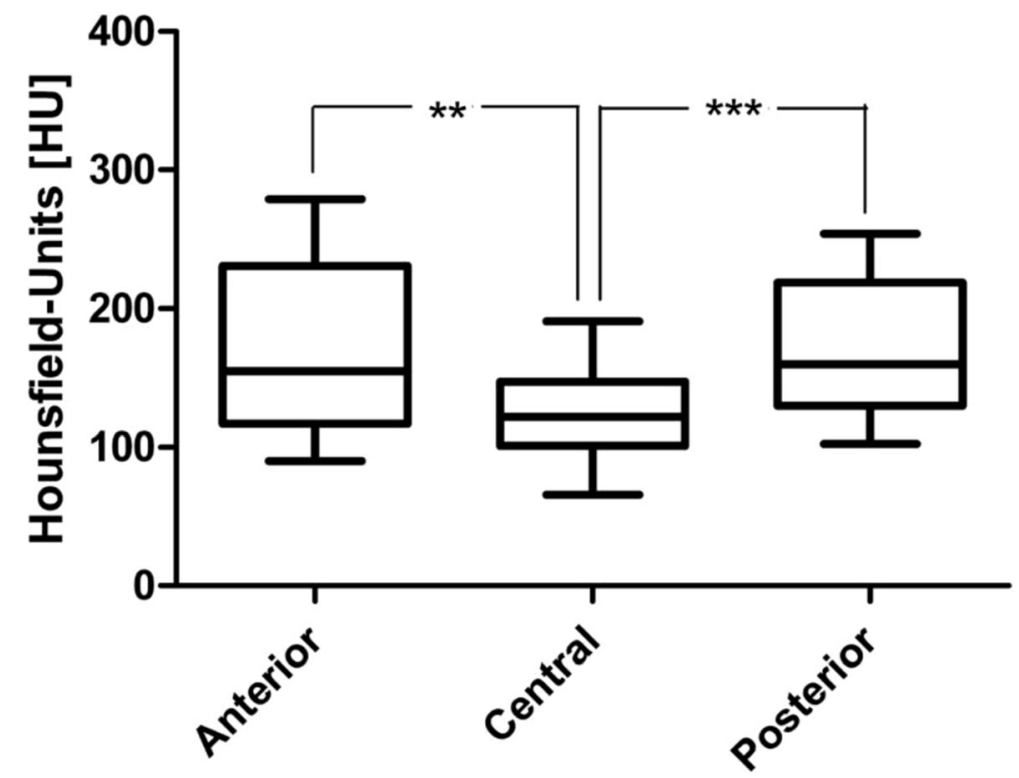

Fig. 5 Anterior-posterior development of HU. Whiskers, 10-90 percentile

depth was 1.5 (SD 0.5) [0.6-2.7]. Only the penetration depth was significantly negative correlated with $\mathrm{HU}(r=-$ 0.31 ; $P=0.023$; Fig. 6 ). On the contrary, there was no significant correlation between the total cement thickness $(r=-0.24 ; P=0.081)$ or cement mantle thickness $(r=$ $0.05 ; P=0.70)$ and bone density $(\mathrm{HU})$.
The average interface proportion without cement penetration in zone 1 was $31.8 \%$ SD $23.7 \%$ [0.0-80.0\%]. The correlation between $\mathrm{HU}$ and the proportion without cement penetration in zone 1 was $r=+0.33(P=0.014$; Fig. 7). Figure 8 shows an SEM image of an implant-cement-bone interface, that provides a morphological

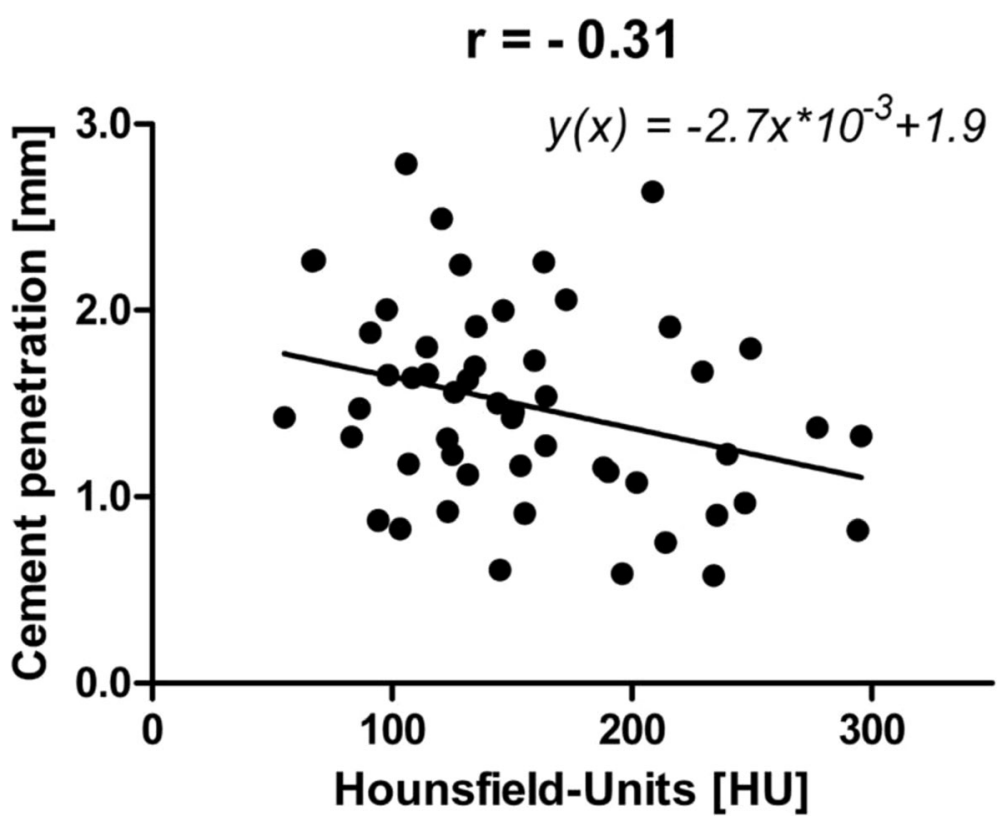

Fig. 6 Correlation between bone density and penetration depth in area 1 


\section{$r=+0.33$}

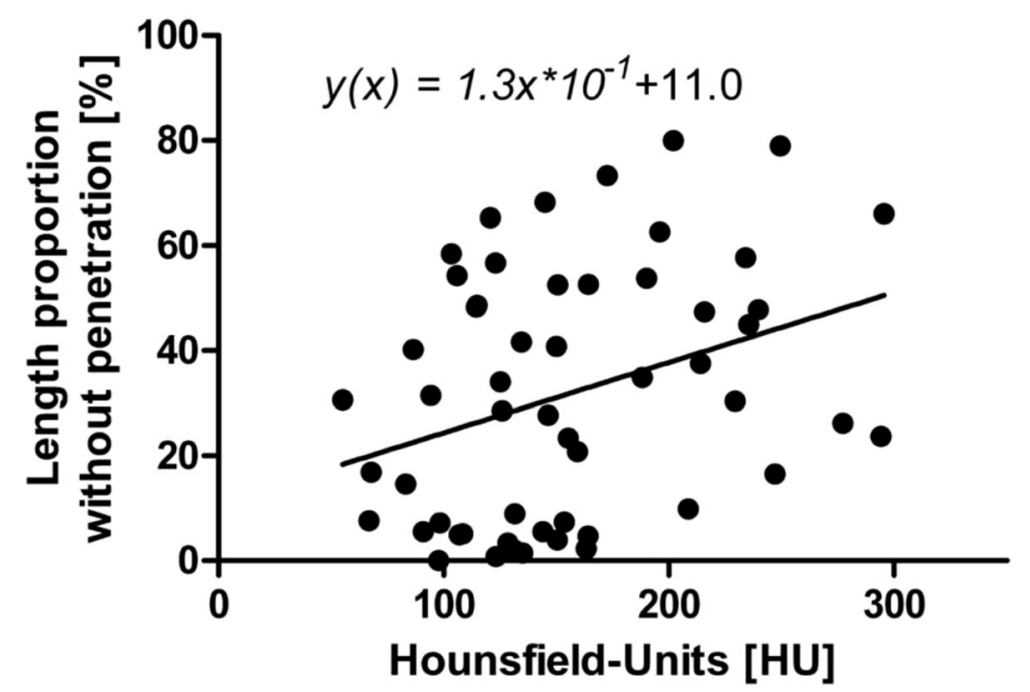

Fig. 7 Correlation of bone density with the interruptions of penetration in area 1

example of an extended area without cement intrusion in zone 1 (specimen no. 9, third cut post; approx. $164 \mathrm{HE}$ ).

The manifestation of visible cement penetration in the area directly adjacent to the anchoring pegs (zone 2) does not significantly correlate with bone density $(r=$ $0.24 ; P=0.3288)$. The absence of penetration in zones 1 and 2 does also not correlate significantly with each other $(r=0.26 ; P=0.3044)$.

\section{Discussion}

In knee arthroplasty, achieving primary stability is crucial to prevent micromotions, which can lead to a vicious circle of membrane formation, micro fractures, radiolucent lines (RLL), and aseptic loosening [18-21]. Both RLLs and aseptic loosening occur earlier on the tibial side than on the femoral side [22, 23], which emphasizes the importance of solid cementation in tibial UKA.

Our results show relevant areas without cement penetration at the bone-cement interface whose occurrence is positively correlated with bone density. In addition, the average cement penetration depth appeared reduced by high bone density. Interestingly, this relationship between bone density and penetration was not found in the surrounding area of the anchoring pegs.

As bone cement has no adhesive properties, fixation is rather achieved by its intrusion into the microstructure of the trabecular bone and its area-wide mechanical interlocking than by a superficial conformity with irregularities of the bone bed [19, 24-26]. In other words, the primary stability of the cemented fixation, measured as resistance to shear and tensile forces, depends on cement penetration into the adjacent trabecular bone, which is therefore is often used as an indicator of biomechanical stability [13, 24, 26-30]. Nagel et al. demonstrated that a mean tibial penetration depth of at least $1.1 \mathrm{~mm}$ is required to maximize the fixation strength [31]. The mean cement penetration depth registered in this study was 1.5 (SD 0.5) mm, which is well above this lower limit of penetration depth and in line with former studies [13, 32].

The extent of cement penetration depth results from the interaction between the cementing technique, cement properties, and bone density. Concerning the cementing technique, it is generally accepted that cleaning of the trabecular resection surfaces is a prerequisite for adequate cement penetration $[13,15,32-34]$. The application of cement to a dry trabecular surface that is free of blood, fat, bone marrow, and debris improves the interlocking of the cement and thus the fixing strength [35-37]. With regard to bone cement, penetration tends to increase with the viscosity of the cement [25, 38-40].

In contrast to the previously mentioned aspects, bone density is a factor that cannot be easily controlled by the surgeon. Penetration is expected to decrease with increasing bone density or decreasing porosity of the bone $[26,28,41]$. However, the specific effect of bone density in minimally invasive implanted UKA with limited intraoperative access, thus restricted the potential of bone preparation and component impaction, remains unclear.

The presented assessment of cement penetration on serial cuts and the quantification of bone density via BMD, which has been adapted for extremities in other studies, can be regarded as well-established methods [15, 19, 42-45]. In 
addition, bone quality was measured via $\mathrm{HU}$ in the anterior, central, and posterior part of the tibial plateau.

The highly significant correlation between $\mathrm{HU}$ and trabecular BMD underlines the applicability of $\mathrm{HU}$ for quantification of bone density $(r=0.93 ; P<0.0001)$. The use of $\mathrm{HU}$ appears attractive as it enables a precise regional quantification of trabecular bone density. In this analysis, it was fundamental for the identification of the significantly increased average bone density in the anterior and posterior area. In combination with the poorer accessibility for jet lavage and the more difficult pressure application, it uncovers the posterior tibial area, analogous to the posterior femoral condyle, as a potential weak point of minimally invasive UKA implantation [11, 15]. As regional HU measurements focused on trabecular areas, the less positive correlation between $\mathrm{HU}$ and cortical BMD seems plausible. The negative correlation between age and bone density did not reach the level of significant, which might be attributable to the rather low case number.

Based on three ROIs per specimen and the analysis of 18 UKAs, the morphologic correlation analysis comprises 54 data points. Our results demonstrate a significantly negative correlation between bone density and penetration depth $(r=-0.31)$. These values correspond to the correlation coefficient reported by Askew et al. $(r=-0.24)$ [28]. To about the same extent, bone density restricts area-wide cement intrusion into the trabecular bone $(r=+0.33)$. Figure 7 shows how the high bone density prevents the cement from penetrating into the interspaces of the bone trabecula and thus prevents a planar interlocking.

The question to what extent the minimally invasive surgical approach, despite the use of jet lavage, impedes the opening of the bone substance, or if available instruments do not allow optimal pressurization of the prosthesis against the bone surface, especially in the posterior area, cannot be answered with the available date. In any case, we recommend the use of drill holes or special devices for microfracturing to prepare anchor wholes during the implantation of UKA in a minimally invasive approach.

Anchoring pegs on the undersurface of the prostheses improve cement penetration largely independent from bone density. Our results demonstrate that in contrast to zone 1 (Fig. 8), there is no significant correlation between bone density and cement penetration around the anchoring peg in zone 2 . Thus, a mechanically promoted penetration in zone 2 may be assumed. This observation and the low correlation between penetration around the peg and underneath the horizontal part of the component prove the sense of a differentiated assessment of the two zones and might influence future prosthetic design, e.g., by adding further anchoring pegs.

Concerning cement application and pressurization, Dorr et al. suggested manual cement application after mixing cement for less than $3 \mathrm{~min}$ and preparing the bone bed with jet lavage [46]. However, Lutz et al. stated in an in vivo study on TKA that the widespread use of manual cement application, despite jet lavage, is not a reliable method to achieve sufficient cement penetration [14]. Experimental in vitro studies also showed that manual cement application leads to lower penetration depths than the use of a cement gun [24]. Due to the minimally invasive approach and the limited surgical field, manual application of bone cement was used in this study and might add to relevant areas without cement penetration in zone 1 . In addition, the choice of a highly viscous Palacos ${ }^{\oplus} \mathrm{R}$ bone cement might also have had a negative influence on penetration. Noble and Swarts doubted that penetration depths of more than 3 $\mathrm{mm}$ are achievable using Palacos and a pressure of 35 $\mathrm{kPa}$, even after excluding all bone specimen with closed intertrabecular spaces [38]. These results are consistent with the highest penetration of $2.7 \mathrm{~mm}$ observed in this study.

\section{Conclusions}

Specimens with high bone density are characterized by a significantly higher interface proportion without visible

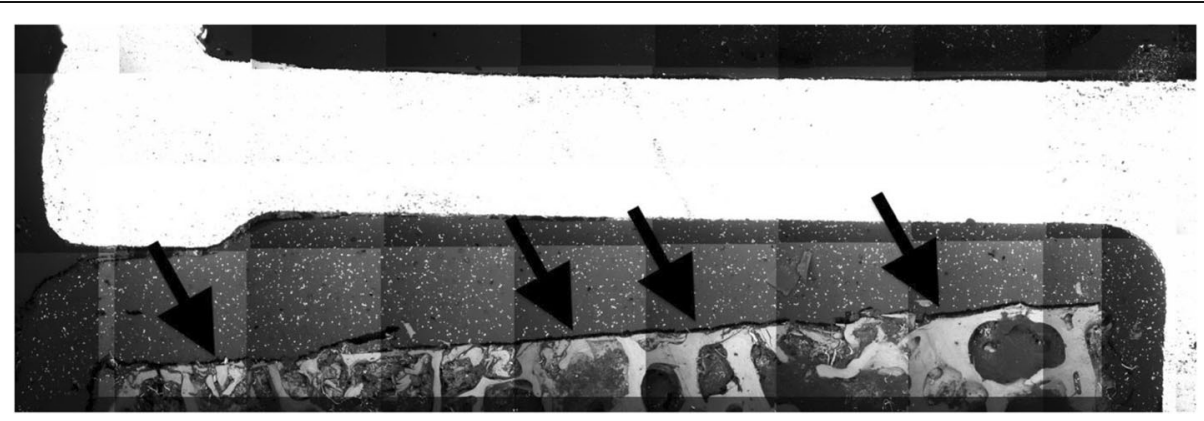

Fig. 8 SEM image, an extended area without cement penetration in area 1. Arrows, examples of how high bone density prevents bone cement from penetrating into the interspaces of the trabecular bone and thus prevents a mechanical interlocking 
penetration and by significantly lower penetration depths in zone 1 . In contrast, bone density does not reduce penetration around the anchoring peg, probably due to mechanical forced pressurization. Going forward, the reported results foster considerations of additional drill holes to open sclerotic bone or the feasibility of pressurized cement application, additional anchoring pegs, or optimized impaction instruments for minimally invasive procedures. Further research is required to assess the balance of bone density and cement penetration with regard to biomechanical stability.

\section{Abbreviations}

BMD: Bone mineral density; CT: Computed tomography; Fig.: Figure; HU: Hounsfield units; ROI: Region of interest; SEM: Scanning electron microscope; TKA : Total knee arthroplasty; UKA: Unicompartmental knee arthroplasty

\section{Acknowledgements}

Not applicable.

\section{Authors' contributions}

Hereby, I confirm that all authors have made substantial contributions to all of the following: (1) the conception and design of the study (CBS, MFP, CS, IL, TMG, PEM) acquisition of the data (CBS, MFP, CS, IL, TMG, PEM), or analysis and interpretation of the data (CBS, MFP, CS, IL, TMG, PEM); (2) drafting the article (CBS, MFP) or revising it critically for important intellectual content (CS, IL, TMG, PEM); and (3) final approval of the version to be submitted (CBS, MFP, CS, IL, TMG, PEM). Furthermore, each of the authors has read and concurs with the content in the final manuscript (CBS, MFP, CS, IL, TMG, PEM).

\section{Funding}

All funding and the execution of the preparation, implantation, and testing were conducted by the Laboratory for Biomechanics and Experimental Orthopaedics of the Ludwig Maximilians University. There was no influence of the manufacturer concerning the design of the study and collection, analysis, and interpretation of data and/or writing this manuscript.

\section{Availability of data and materials}

The datasets used and/or analyzed during the current study are available from the corresponding author on reasonable request.

\section{Ethics approval and consent to participate}

The study concept was presented to the local ethics committee of the Ludwig Maximilians University of Munich (Chairman: Prof. Dr. W. Eisenmenger) and received approval. This approval included consent to the use of human tissue (cadaver legs). The human tissue involved in this study was obtained from the Department of Pathology of the Ludwig Maximilians University of Munich. No tissue was obtained from prisoners.

\section{Consent for publication}

Not applicable.

The presented manuscript does not include any details, images, or videos relating to an individual person. The specimens pictured are entirely unidentifiable and there are no details on individuals reported within the manuscript.

\section{Competing interests}

One author (PEM) is an advising surgeon of Aesculap R\&D projects. Two of the authors (MFP; PEM) are getting research funding in correlation with Aesculap R\&D projects. The other authors declared no conflict of interest.

\section{Author details}

'Department of Orthopaedics, Physical Medicine and Rehabilitation, University Hospital, LMU Munich, Munich, Germany. ${ }^{2}$ Department of Orthopedics and Sports Orthopedics, Klinikum rechts der Isar, Technical
University Munich, Ismaninger Str. 22, 81675 Munich, Germany. ${ }^{3}$ Aesculap AG Research \& Development, Am Aesculap-Platz, 78532 Tuttlingen, Germany.

Received: 21 July 2019 Accepted: 13 September 2019

Published online: 22 October 2019

\section{References}

1. Robertsson O, Borgquist L, Knutson K, Lewold S, Lidgren L. Use of unicompartmental instead of tricompartmental prostheses for unicompartmental arthrosis in the knee is a cost-effective alternative. 15,437 primary tricompartmental prostheses were compared with 10,624 primary medial or lateral unicompartmental prostheses. Acta Orthop Scand. 1999;70(2):170-5.

2. Mohammad HR, Strickland L, Hamilton TW, Murray DW. Long-term outcomes of over 8,000 medial Oxford Phase 3 Unicompartmental Knees-a systematic review. Acta Orthop. 2018;89(1):101-7.

3. Inacio MCS, Paxton EW, Graves SE, Namba RS, Nemes S. Projected increase in total knee arthroplasty in the United States - an alternative projection model. Osteoarthr Cartil. 2017;25(11):1797-803.

4. Brown NM, Sheth NP, Davis K, Berend ME, Lombardi AV, Berend KR, Della Valle CJ. Total knee arthroplasty has higher postoperative morbidity than unicompartmental knee arthroplasty: a multicenter analysis. J Arthroplast. 2012;27(8 Suppl):86-90.

5. Ghomrawi HM, Eggman AA, Pearle AD. Effect of age on cost-effectiveness of unicompartmental knee arthroplasty compared with total knee arthroplasty in the U.S. J Bone Joint Surg Am. 2015;97(5):396-402.

6. Kim KT, Lee S, Lee Jl, Kim JW. Analysis and treatment of complications after unicompartmental knee arthroplasty. Knee Surg Relat Res. 2016;28(1):46-54.

7. Epinette JA, Brunschweiler B, Mertl P, Mole D, Cazenave A, French Society for $\mathrm{H}$, Knee. Unicompartmental knee arthroplasty modes of failure: wear is not the main reason for failure: a multicentre study of 418 failed knees. Orthop Traumatol Surg Res. 2012;98(6 Suppl):S124-30.

8. Saenz CL, McGrath MS, Marker DR, Seyler TM, Mont MA, Bonutti PM. Early failure of a unicompartmental knee arthroplasty design with an allpolyethylene tibial component. Knee. 2010;17(1):53-6.

9. van der List JP, Zuiderbaan HA, Pearle AD. Why do medial unicompartmental knee arthroplasties fail today? J Arthroplast. 2016;31(5):1016-21.

10. Liddle AD, Judge A, Pandit H, Murray DW. Adverse outcomes after total and unicompartmental knee replacement in 101,330 matched patients: a study of data from the National Joint Registry for England and Wales. Lancet. 2014;384(9952):1437-45.

11. Scheele C, Pietschmann MF, Schroder C, Grupp T, Holderied M, Jansson V, Muller PE. Effect of minimally-invasive implantation of unicompartmental knee arthroplasty on cement penetration and biomechanical stability. An experimental study in human tibiae. Clin Biomech (Bristol, Avon). 2018;51:34-9.

12. Vanlommel J, Luyckx JP, Labey L, Innocenti B, De Corte R, Bellemans J. Cementing the tibial component in total knee arthroplasty: which technique is the best? J Arthroplast. 2011;26(3):492-6.

13. Schlegel UJ, Siewe J, Delank KS, Eysel P, Puschel K, Morlock MM, de Uhlenbrock AG. Pulsed lavage improves fixation strength of cemented tibial components. Int Orthop. 2011;35(8):1165-9.

14. Lutz MJ, Pincus PF, Whitehouse SL, Halliday BR. The effect of cement gun and cement syringe use on the tibial cement mantle in total knee arthroplasty. J Arthroplast. 2009;24(3):461-7.

15. Clarius M, Mohr G, Jaeger S, Seeger JB, Bitsch RG. Femoral fixation pattern in cemented Oxford unicompartmental knee arthroplasty--an experimental cadaver study. Knee. 2010;17(6):398-402.

16. Grupp TM, Pietschmann MF, Holderied M, Scheele C, Schroder C, Jansson V, Muller PE. Primary stability of unicompartmental knee arthroplasty under dynamic compression-shear loading in human tibiae. Clin Biomech (Bristol, Avon). 2013;28(9-10):1006-13.

17. Scheele C, Pietschmann MF, Schroder C, Grupp T, Holderied M, Jansson V, Muller PE. Effect of lavage and brush preparation on cement penetration and primary stability in tibial unicompartmental total knee arthroplasty: an experimental cadaver study. Knee. 2017;24(2):402-8.

18. Hori RY, Lewis JL. Mechanical properties of the fibrous tissue found at the bone-cement interface following total joint replacement. J Biomed Mater Res. 1982:16(6):911-27.

19. Miller MA, Terbush MJ, Goodheart JR, Izant TH, Mann KA. Increased initial cement-bone interlock correlates with reduced total knee arthroplasty micro-motion following in vivo service. J Biomech. 2014;47(10):2460-6. 
20. Anthony PP, Gie GA, Howie CR, Ling RS. Localised endosteal bone lysis in relation to the femoral components of cemented total hip arthroplasties. $J$ Bone Joint Surg Br. 1990;72(6):971-9.

21. Star MJ, Colwell CW Jr, Kelman GJ, Ballock RT, Walker RH. Suboptimal (thin) distal cement mantle thickness as a contributory factor in total hip arthroplasty femoral component failure. A retrospective radiographic analysis favoring distal stem centralization. J Arthroplast. 1994;9(2):143-9.

22. Bini SA, Cafri G, Khatod M. Midterm-adjusted survival comparing the best performing unicompartmental and total knee arthroplasties in a registry. J Arthroplast. 2017:32(11):3352-5

23. Kleeblad LJ, van der List JP, Zuiderbaan HA, Pearle AD. Regional femoral and tibial radiolucency in cemented unicompartmental knee arthroplasty and the relationship to functional outcomes. J Arthroplast. 2017;32(11):3345-51.

24. Krause WR, Krug W, Miller J. Strength of the cement-bone interface. Clin Orthop Relat Res. 1982;(163);163:290-9.

25. Markolf KL, Amstutz HC. Penetration and flow of acrylic bone cement. Clin Orthop Relat Res. 1976;121:99-102.

26. Walker PS, Soudry M, Ewald FC, McVickar H. Control of cement penetration in total knee arthroplasty. Clin Orthop Relat Res. 1984;185:155-64.

27. Panjabi MM, Cimino WR, Drinker H. Effect of pressure on bone cement stiffness. An in vitro study. Acta Orthop Scand. 1986;57(2):106-10.

28. Askew MJ, Steege JW, Lewis JL, Ranieri JR, Wixson RL. Effect of cement pressure and bone strength on polymethylmethacrylate fixation. J Orthop Res. 1984;1 (4):412-20.

29. MacDonald W, Swarts E, Beaver R. Penetration and shear strength of cement-bone interfaces in vivo. Clin Orthop Relat Res. 1993;286:283-8.

30. Mann KA, Ayers DC, Werner FW, Nicoletta RJ, Fortino MD. Tensile strength of the cement-bone interface depends on the amount of bone interdigitated with PMMA cement. J Biomech. 1997;30(4):339-46.

31. Nagel K, Bishop NE, Schlegel UJ, Puschel K, Morlock MM. The influence of cement morphology parameters on the strength of the cement-bone Interface in tibial tray fixation. J Arthroplast. 2017:32(2):563-569 e561.

32. Maistrelli GL, Antonelli L, Fornasier V, Mahomed N. Cement penetration with pulsed lavage versus syringe irrigation in total knee arthroplasty. Clin Orthop Relat Res. 1995;312:261-5.

33. Miskovsky C, Whiteside LA, White SE. The cemented unicondylar knee arthroplasty. An in vitro comparison of three cement techniques. Clin Orthop Relat Res. 1992;284:215-20.

34. Seeger JB, Jaeger S, Bitsch RG, Mohr G, Rohner E, Clarius M. The effect of bone lavage on femoral cement penetration and interface temperature during Oxford unicompartmental knee arthroplasty with cement. J Bone Joint Surg Am. 2013;95(1):48-53.

35. Majkowski RS, Miles AW, Bannister GC, Perkins J, Taylor GJ. Bone surface preparation in cemented joint replacement. J Bone Joint Surg Br. 1993; 75(3):459-63.

36. Stannage K, Shakespeare D, Bulsara M. Suction technique to improve cement penetration under the tibial component in total knee arthroplasty. Knee. 2003;10(1):67-73.

37. Ritter MA, Herbst SA, Keating EM, Faris PM. Radiolucency at the bonecement interface in total knee replacement. The effects of bone-surface preparation and cement technique. J Bone Joint Surg Am. 1994;76(1):60-5.

38. Noble PC, Swarts E. Penetration of acrylic bone cements into cancellous bone. Acta Orthop Scand. 1983;54(4):566-73.

39. Halawa M, Lee AJ, Ling RS, Vangala SS. The shear strength of trabecular bone from the femur, and some factors affecting the shear strength of the cement-bone interface. Arch Orthop Trauma Surg. 1978;92(1):19-30.

40. Silverman EJ, Landy DC, Massel DH, Kaimrajh DN, Latta LL, Robinson RP. The effect of viscosity on cement penetration in total knee arthroplasty, an application of the squeeze film effect. J Arthroplast. 2014;29(10): 2039-42.

41. Panjabi MM, Goel VK, Drinker H, Wong J, Kamire G, Walter SD. Effect of pressurization on methylmethacrylate-bone interdigitation: an in vitro study of canine femora. J Biomech. 1983;16(7):473-80.

42. Banwart JC, McQueen DA, Friis EA, Graber CD. Negative pressure intrusion cementing technique for total knee arthroplasty. J Arthroplast. 2000;15(3):360-7.

43. Scheele CB, Muller PE, Schroder C, Grupp T, Jansson V, Pietschmann MF. Accuracy of a non-invasive CT-based measuring technique for cement penetration depth in human tibial UKA. BMC Med Imaging. 2019;19(1):9.
44. Pietschmann MF, Frohlich V, Ficklscherer A, Gulecyuz MF, Wegener B, Jansson V, Muller PE. Suture anchor fixation strength in osteopenic versus non-osteopenic bone for rotator cuff repair. Arch Orthop Trauma Surg. 2009:129(3):373-9.

45. Pietschmann MF, Gulecyuz MF, Fieseler S, Hentschel M, Rossbach B, Jansson V, Muller PE. Biomechanical stability of knotless suture anchors used in rotator cuff repair in healthy and osteopenic bone. Arthroscopy. 2010;26(8):1035-44.

46. Dorr LD, Lindberg JP, Claude-Faugere M, Malluche HH. Factors influencing the intrusion of methylmethacrylate into human tibiae. Clin Orthop Relat Res. 1984;183:147-52.

\section{Publisher's Note}

Springer Nature remains neutral with regard to jurisdictional claims in published maps and institutional affiliations.
Ready to submit your research? Choose BMC and benefit from:

- fast, convenient online submission

- thorough peer review by experienced researchers in your field

- rapid publication on acceptance

- support for research data, including large and complex data types

- gold Open Access which fosters wider collaboration and increased citations

- maximum visibility for your research: over $100 \mathrm{M}$ website views per year

At BMC, research is always in progress.

Learn more biomedcentral.com/submissions 